\title{
Heat treatment and associated early modern human behaviors in the Late Paleolithic at the Shuidonggou site
}

\author{
ZHOU ZhenYu ${ }^{1,2}$, GUAN Ying ${ }^{1}$, GAO Xing $^{1 *} \&$ WANG ChunXue ${ }^{3}$ \\ ${ }^{1}$ Laboratory of Human Evolution, the Institute of Vertebrate Paleontology and Paleoanthropology, Chinese Academy of Sciences, \\ Beijing 100044, China; \\ ${ }^{2}$ Institute of Archaeology, Chinese Academy of Social Sciences, Beijing 100710, China; \\ ${ }^{3}$ Research Center of Chinese Frontier Archaeology of Jilin University, Changchun 130012, China
}

Received May 18, 2012; accepted September 25, 2012; published online January 10, 2013

\begin{abstract}
Unearthed artifacts and cultural relics from the Shuidonggou site revealed extensive information and insights regarding the activities of early modern humans. A series of experimental research and physical analysis suggest that stone artifacts from Locality 2 and Locality 12 have undergone heat treatment. The utilization ratio and knapping properties of raw materials were consequently enhanced. Heat treatment technology reflects the production capacities and the survival strategies in the Upper Paleolithic period. This discovery indicates the earliest existence of this technology in the East Asia and thus confirms a wider geographic distribution of this technology which provides new perspectives and evidence for understanding the associated early modern human behaviors.
\end{abstract}

Paleolithic, early modern human behavior, heat treatment, technological dispersal

Citation: Zhou Z Y, Guan Y, Gao X, et al. Heat treatment and associated early modern human behaviors in the Late Paleolithic at the Shuidonggou site. Chin Sci Bull, 2013, 58: 1801-1810, doi: 10.1007/s11434-012-5522-3

The emergence of early modern human behavior was a result of the coevolution of physics and intelligence as a necessary response to environment, and it was a vital strategy for surviving in the cruel Paleolithic period. Behaviors and traits considered useful in identifying modern human behavior include: Symbolic and decorated artifact production [1-4], worked bone and antler production, blade technology, standardization of artifact types, artifact diversity, complex hearth construction, organized use of domestic space, expanded exchange networks, effective large-mammal exploitation, seasonally focused mobility strategies, use of harsh environments, and fishing and fowling [5-14]. The heat treatment technology provided technical support for the origin and evolution of early modern human behaviors and is correlated with it through time. In terms of Paleolithic archaeology, the heat treatment technology refers to the alteration of outside external features and internal properties

*Corresponding author (email: gaoxing@ivpp.ac.cn) of lithic materials through heating, heat insulation, and cooling for the purpose of catering to the growing requirement of lithic reduction and satisfying the cognitive and symbolic needs of ancient knappers. Therefore, the discussion of Paleolithic heat treatment becomes a vital path for interpreting prehistoric societies and the Paleolithic economic situation. Heat treatment technology indicates a deep utilization of lithic materials by ancient human beings and therefore is considered as one of the early modern human behaviors. The study of this technology could also help us understand early modern human capacities in terms of raw material selection, cognition, development level of lithic knapping, and abilities of resource exploitation. Consequently, this will allow us to interpret the behavioral model and the social organization of our ancestors.

The earliest heat treatment of stone materials has been found in South Africa, appearing as early as $164 \mathrm{ka}$, predominantly for silcrete tools, 72 ka years ago in Still Bay, South Africa [15]. Since use and control of fire are the kinds 
of behavior considered to be important for human evolution, deliberate heating of materials to improve their properties is a representative of modern human behavior. In addition, heat treatment of stone tools has also been found at middle Paleolithic sites in Africa and Europe. In the Late Paleolithic, heat treatment technology has been distributed in most parts of the world, including the American continent, Siberia, India, Pakistan, and Afghanistan [16-19], with the exception of East Asia. In this paper, hundreds of heat-treated artifacts unearthed from the Ningxia Shuidonggou site were identified by simulation experiment, laboratory tests and microscopic observation. This finding for the first time confirms the existence of heat treatment behavior dating back 20000 years in East Asia. This discovery provides significant support for discussing the behavioral models of ancient occupants in Northern China, and it provides evidence for the appearance of early modern human behaviors and their manifestations in China.

\section{Archaeological context}

The Shuidonggou site is located in the eastern margin of Yinchuan basin, which is southwest of the Mu Us Dessert. The site is $28 \mathrm{~km}$ east to Yinchuan City, the capital of the Ningxia Hui Autonomous Region (subsequently referred to as Ningxia), Northeast China (Figure 1).

Locality 2 of Shuidonggou site (SDG 2 hereafter) recorded heat treatment of stone artifacts in anthropogenic layers 1 to 4, which has been dated to 29-20 ka BP. The dominant specimens are from layer 1 which is about $20 \mathrm{ka} \mathrm{BP}$; Locality 12 at the Shuidonggou site (SDG 12 hereafter) is about 11 ka BP [20,21], and locality 8 at the Shuidonggou site (SDG 8 hereafter) is about 27-20 ka BP based on the comparison of stratum and cultural relics with other localities [22].

The dominated raw materials in SDG are dolomite and chert. Based on the geological data and geological surveys $[23,24]$, there is no exposure of these two types of base rock. From the survey, pebble layers were found in the profiles of each terrace in addition to high-level polished pebbles, which presented all types of rocks. We thus proposed that these pebble layers were the sources of stone artifact raw materials during the period of occupation.

During 20-thousand-year occupation of this site by early modern humans, blade technology, small-flake-tool technology, and micro-blade technology appeared in succession. Additionally, ostrich egg shell bead decorations coexisted with these stone knapping techniques. Besides dolomite and chert, raw materials also include quartz sandstone, quartzite and siliceous limestone. Hearth relics were also discovered in the SDG site, suggesting the ability of fire control by ancient occupants [25-30], which built the foundation for lithic heat treatment technology. This technology, well developed 30 thousand years ago in Europe, Africa, and Middle Asia, raised the efficiency of knapping, especially for the production of blade and micro-blade. The SDG site has been noted for the western-styled lithic factors (e.g. blade technique) found here. These factors could be traced to Middle Asia and Siberia-Mongolia Plateau due to similarities in lithic technologies as heat treatment technology was recently well-developed in these areas. In this framework, the SDG materials are chosen for this study.

\section{Materials and methods}

\subsection{Materials}

This study comprises both unearthed archaeological specimens and experimental specimens. Since it was discovered in the last century, the SDG site has been systematically excavated 8 times, yielding a rich collection of unearthed materials. In this study, we select lithic artifacts from SDG 2, SDG 8 and SDG 12 for the analysis. The rock types are

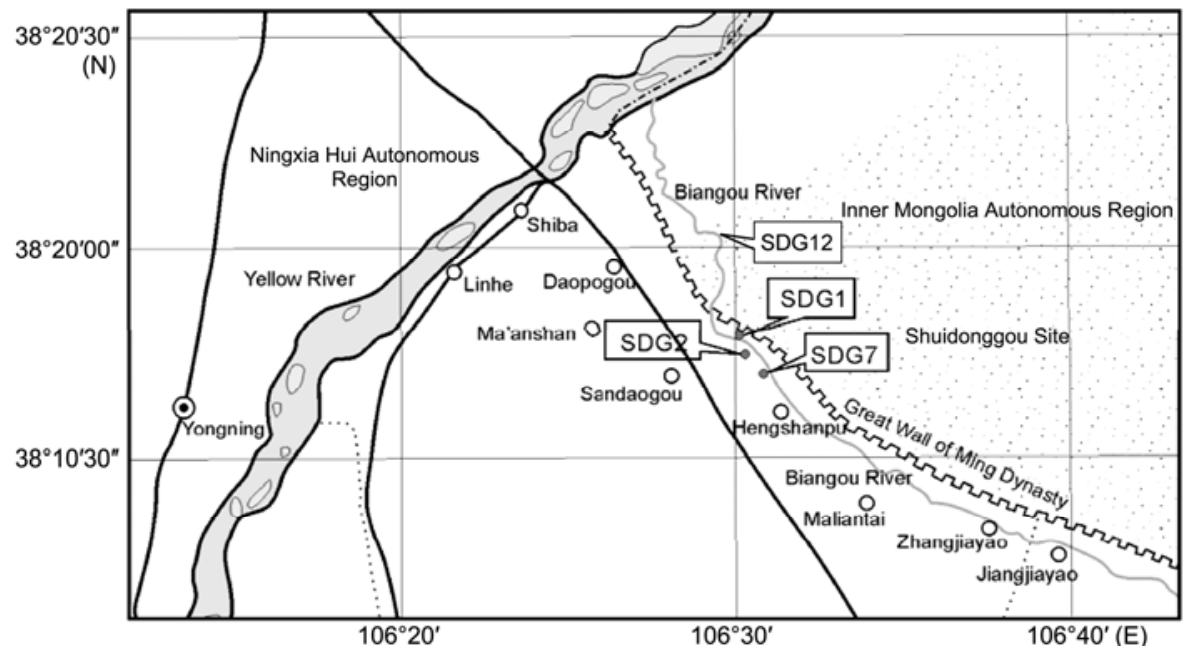

Figure 1 The geographic location of Shuidonggou site [20]. 
mostly dolomite, chert, quartz, quartz sandstone and siliceous limestone. The typology refers to core, micro-blade core, flake, micro-blade, retouched tool, etc. The typological analysis and examination are still on-going; we thus could not cover the whole assemblage. To avoid the subjective discrimination in terms of sampling, the samplings are conducted on all typological types.

On the other hand, the experimental specimens are pebbles collected from pebble layers near SDG 2 and SDG 12 in terrace 2 and 3. The rock types include dolomite, chert, quartz and quartz sandstone.

\subsection{Testing procedures}

To study the macro- and micro-changes of lithic raw materials subjected to heat treatment, an experiment was developed in which indoor and outdoor experimental environments were set up. According to archeological and ethnological evidence, two open-air hearths were built on sandy sediment. Hearth B was an open hearth, and hearth A was a stone-lined hearth with ventilators (Figure 2). Rapid cooling or heating during heat treatment can generate heat damage. So, some pebbles and flakes were buried in sands at a depth of $3-5 \mathrm{~cm}$ in the centre of the hearth to avoid rapid temperature change. At the same time, some flakes which were taken as unintentionally heated samples were heated directly in the fire. The intentionally heat-treated specimens will be compared with the unintentionally heated specimens. During testing, and because of the distribution of the sands, the peak temperature of the hearth $\left(600^{\circ} \mathrm{C}\right)$ was higher than the buried pebbles $\left(400^{\circ} \mathrm{C}\right)$ because of the sands above them. In hearth $\mathrm{A}$, the open fire lasted for $10 \mathrm{~h}$, and the pebbles buried with sands cooled slowly. $16 \mathrm{~h}$ later, the heated specimens cooled to air temperature. In hearth $\mathrm{B}$, the open fire lasted for $8 \mathrm{~h}$ and was then allowed to cool slowly in the open air for $6 \mathrm{~h}$ until the specimens cooled to air temperature. A TM902C thermodetector was used to record the realtime experiment temperature.

During indoor testing, experimental samples were heated in a GW-300C electric resistance furnace to peak temperature from 30 to $550^{\circ} \mathrm{C}\left(50^{\circ} \mathrm{C}\right.$ for a gradient $)$ with a starting temperature of $100^{\circ} \mathrm{C}$ at two different heating rates $(50$ and $100^{\circ} \mathrm{C} / \mathrm{h}$ ). The furnace held peak temperature for $2 \mathrm{~h}$. Thereafter, in fast-cooling experiments, we removed the heated blanks out and, over the course of approximately $3 \mathrm{~h}$, allowed them to cool to air temperature. In the slow-cooling experiment, we left the heated blanks in the closed furnace and, over the course of approximately $14 \mathrm{~h}$, allowed them to cool to air temperature. All experimental pebbles were split into pieces before heat treatment, and then these pieces were heated separately in different temperatures and cooled down at different rates.

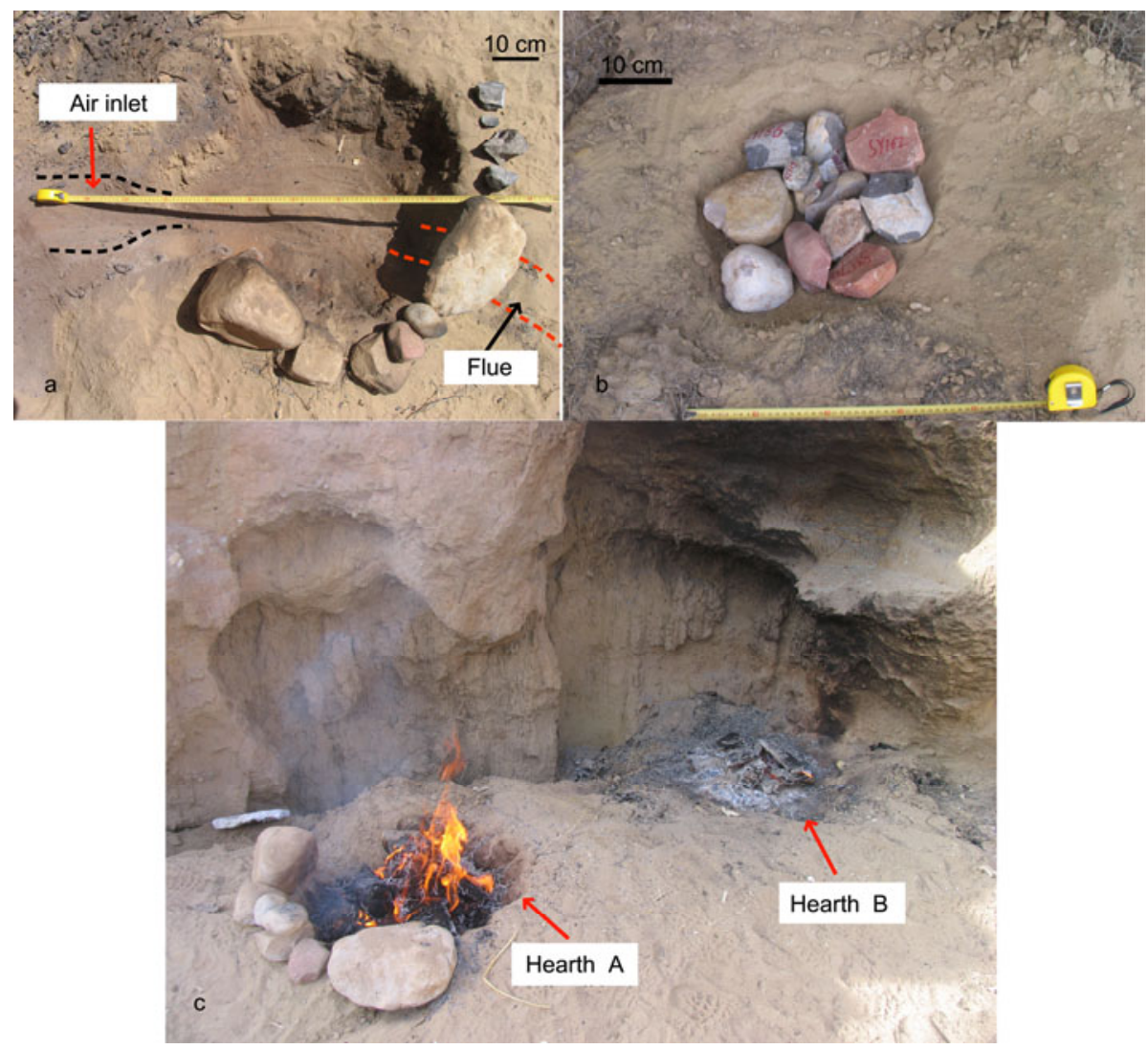

Figure 2 Experiment hearths. a, Hearth A; b, hearth B; c, experiment hearths. 


\subsection{Visual changes}

Some changes are visible by unaided eyes: changes in colour; greasy lustre on heated siliceous rocks; heat damage; and retardation or acceleration of patination. The colour changes were identified using the Munsell Soil Chart. We could also identify some changes in the heated artifacts from a lithic analysis perspective: (1) damage such as complete disintegration, potlid fracture, flake splitting, transverse fracture, surface crazing; and (2) heated raw material could yield more flakes with less force, and the flakes will be longer than the onefrom unheated material $[31,32]$.

\subsection{Microscopic observations}

In addition to the visual changes, microstructural changes accompanying heat treatment could be detected by X-ray diffraction, infra-red absorption spectroscopy or scanning electron microscopy. The changes at the microcrystalline level, including crystal size and constructure which heat treatment affects, can be observed under the scanning electron microscope [33-35]. Comparisons between raw and heated specimens at these magnifications seem to yield fairly certain results.

\section{Results}

\subsection{Visual changes}

This heat treatment experiment study showed that there was consistent colour change during heat treating by furnace. In 57 pieces of heat-treated blanks, the colour of $67 \% \quad(n=38)$ of the pieces turned red (Table 1), and all specimens which were heat treated to $350-400^{\circ} \mathrm{C}$ turned red (Figure 3 ). The colours of dolomite blanks which were heated to 300$550^{\circ} \mathrm{C}$ changed from reddish gray $(2.5 \mathrm{YR} 5 / 1)$ or gray $(5$ YR 5/1) to pale red (10 R 7/2) or weak red (10 R 5/3); chert and chalcedony which were heat treated to $300-400^{\circ} \mathrm{C}$ changed from dark gray (N/4) to red (2.5 YR 5/8) (Figure 4). In contrast, there was no significant colour change of heat treated quartzite and quartzite sandstone. Experimental heating of all SDG knappable toolstones to the peak temperature of $300-500^{\circ} \mathrm{C}$ at a slow heating and cooling rate

Table 1 Visual changes statistics of the indoor experiment specimens

\begin{tabular}{lclc}
\hline \multicolumn{1}{c}{$\begin{array}{c}\text { Raw material } \\
\text { type }\end{array}$} & $\begin{array}{c}\text { Heat peak } \\
\text { temperature }\left({ }^{\circ} \mathrm{C}\right)\end{array}$ & Turned red & Heat damage \\
\hline \multirow{2}{*}{ Dolomite } & $450-550$ & $83 \%(n=24 / 29)$ & $14 \%(n=4 / 29)$ \\
& $300-400$ & $80 \%(n=8 / 10)$ & - \\
Cher/chalcedony & $450-550$ & $25 \%(n=2 / 8)$ & - \\
Quartzite sandstone & 550 & $100 \%(n=2 / 2)$ & - \\
Quartzite & 550 & $0 \%(n=0 / 4)$ & - \\
\hline
\end{tabular}

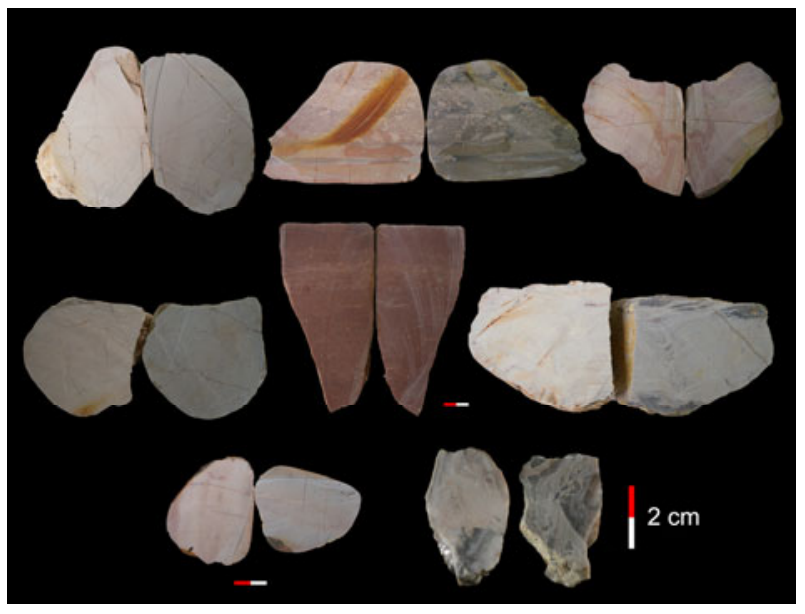

Figure 3 Comparison of raw and indoor experiment heat-treated samples.



Figure 4 Comparison of raw and indoor experiment heat-treated samples (chert). a, Before heating; $b$, after heating.

caused no heat damage. Thermal breakage was found on four heat-treated blanks of dolomite, including one of potlid fracture, when heated to the peak temperature of $550^{\circ} \mathrm{C}$ (Table 1). The experimental results revealed that controlled heating and cooling cause little or no heat damage. A large amount of thermal fracture flakes in situ may be caused by unintentional heating.

Of 67 blanks which were heat treated in the outdoor hearth, 55\% turned red which changed from gray (7.5 YR $5 / 1)$ to reddish gray (5 YR 5/2) or weak red (2.5 YR 5/2). The most common change in previous experiments is from yellow/brown to red. In this study, some of the raw materials were dark gray or black, and this may be the reason that the colour of $45 \%$ of the heated blanks did not change.

With regard to those flakes that we placed directly in the fire so as to replicate unintentional heating, we observed 
irregularities in the visual features. Of the 36 such pieces, $36 \%(n=36)$ changed to red, $7 \%$ turned to light gray due to excessive oxidation, and 50\% appeared carbon black on the surface (Figure 5) (Table 2). Weak greasy lustre was observed on the surface of 10 flakes, and 6 flakes presented heat damage such as fractures or cracks.

The indoor experiment results suggest that colour change should be an effective identification for heat-treated stone artifacts, especially heated to the peak temperature of 300$400^{\circ} \mathrm{C}$. By comparison, the outdoor experiment results showed lower regularity, which may be due to the poor control of fire. The specimens that were heated unintentionally presented different characteristics compared to intentionally heat treated ones, such as thermal breaking and black carbonization. Although the heat-treated artifacts could be identified by visual changes, additional objective meth- ods should be applied to verify the results.

\subsection{Microscopic observations}

Some research suggests that increased lustre is a reliable method for identifying heat-treated artifacts [36]. However, results from this study indicated that turning red is the most remarkable and consistent feature of SDG heat-treated specimens. Therefore, heat-treated artifacts were identified based on the criterion of colour change. To verify our identifications of heat-treated artifacts, the raw/heated experimental specimens and unearthed artifacts were analyzed using a scanning electron microscope.

The unheated experimental specimens presented panidiomorphic to hypidiomorphic laminate structure under SEM, composed of crystals averaging $2-5 \mu \mathrm{m}$ across. The



Figure 5 Unintentionally heated flakes.

Table 2 Visual changes statistics of the outdoor experiment specimens

\begin{tabular}{|c|c|c|c|c|}
\hline Heating method & Raw material type & Turned red & Heat damage & Lustre \\
\hline \multirow{4}{*}{ Heat treated } & dolomite & $70 \%(n=17 / 25)$ & - & - \\
\hline & cher/chalcedony & $25 \%(n=5 / 22)$ & - & - \\
\hline & quartzite sandstone & $0 \%(n=10 / 12)$ & - & - \\
\hline & quartzite & $0 \%(n=5 / 8)$ & - & - \\
\hline \multirow{6}{*}{ Unintentionally heating } & subtotal & $55 \%(n=37 / 67)$ & & \\
\hline & dolomite & $38 \%(n=7 / 18)$ & $28 \%(n=5 / 18)$ & $32 \%(n=4 / 18)$ \\
\hline & cher/chalcedony & $28 \%(n=2 / 7)$ & - & $57 \%(n=4 / 7)$ \\
\hline & quartzite sandstone & $33 \%(n=2 / 6)$ & - & $33 \%(n=2 / 6)$ \\
\hline & quartzite & $40 \%(n=2 / 5)$ & $20 \%(n=1 / 5)$ & - \\
\hline & subtotal & $36 \%(n=13 / 36)$ & $17 \%(n=6 / 36)$ & $28 \%(n=10 / 36)$ \\
\hline
\end{tabular}


crystals show heterogranular texture with subangual edges and an overall moderate directive property. The crystallayers presented flat and closer superposition. The $350^{\circ} \mathrm{C}$ heated specimens presented panidiomorphic to hypidiomorphic slaty structure, composed of crystals averaging 2$8 \mu \mathrm{m}$ cross; the crystals show homogranular and subrounded texture, with an overall moderate directive property. The crystal layers presented flat and closer superposition. Fusion phenomenon appears on the crystal edge after heating, and the boundary thus become fuzzy and hard to discern. The crystals also compacted into a flat plane; this process under $400^{\circ} \mathrm{C}$ is basically the same as $350^{\circ} \mathrm{C}$ but with greater fusion and smoother crystal-plane (Figure 6).

The characteristics of heat-treated unearthed stone artifacts under the SEM are virtually the same as experiment specimens, whether the raw material is flint or dolomite. The SEM image of heated stone artifacts shows that the grains became more even and presented homogranular texture with subrounded edges. The fusion phenomenon and a smoother, flat surface was clearly observed (Figure 7). Similarity was also found between unheated experiment specimens with unearthed ones (Figure 8). These microstructural changes caused by heating were more remarkable on flint specimens.

The SEM examination proved heat treatment behavior at the SDG site and suggests that colour changes are efficient for identifying heated stone artifacts at SDG.

\subsection{Heated archaeological specimens}

After the analysis (external observation and electronic microscopic scanning) and comparison to the experimental and archaeological specimens, 110 pieces of stone artifacts from SDG 2 and SDG 12 are determined as have undergone heat treatment (Figure 9). Artifacts from SDG 8 are also examined, but no such specimens were found.

Analysis of external features and electronic microscope scanning could help to identify if a specimen has been undergone heat treatment. So far, there is no specific method to distinguish intensive heat treatment activity from coincident burning. Therefore, other parameters such as spatial analysis are needed for conclusive determination. Guan et al. [37] have discussed the intra-site functional organization of SDG 2. We reconstructed the 3-dimensional distribution of heated stone artifacts and found that these specimens are all located outside of the central hearth. We thus consider that these specimens were not burnt unintentionally in the central hearth.

Having evaluated the experimental and archaeological specimens using electronic microscopic scanning and archaeological analysis, we identified 110 pieces of artifacts that have undergone heat treatment from SDG $2(n=45)$ and
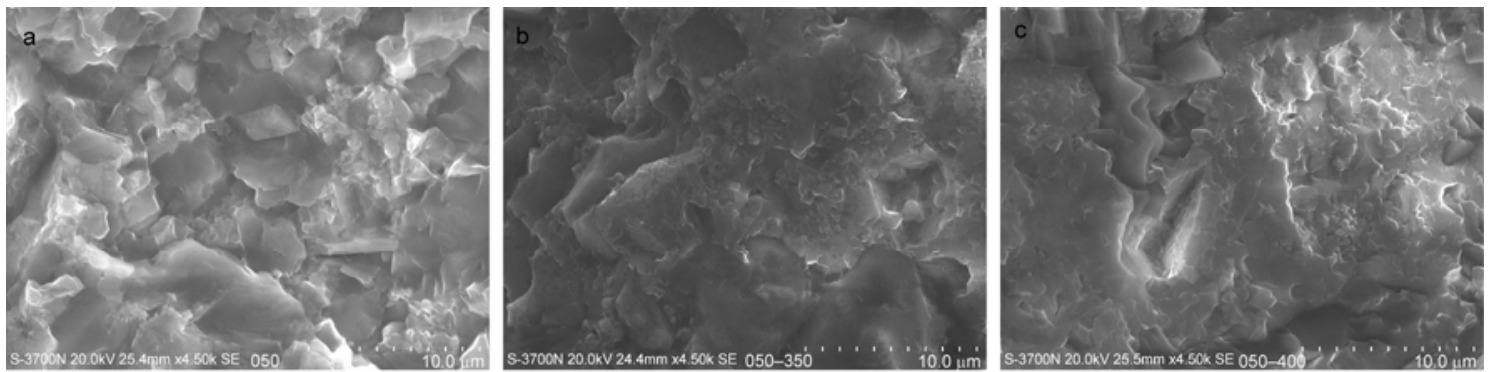

Figure 6 Images of raw (a) and heated $350^{\circ} \mathrm{C}(\mathrm{b}), 400^{\circ} \mathrm{C}$ (c) under SEM.

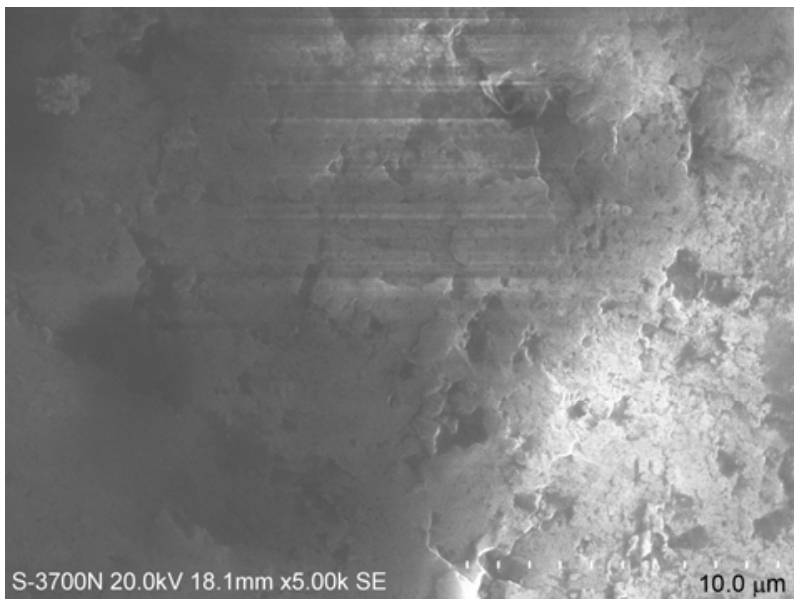

Figure 7 Image of SDG12L3 under SEM

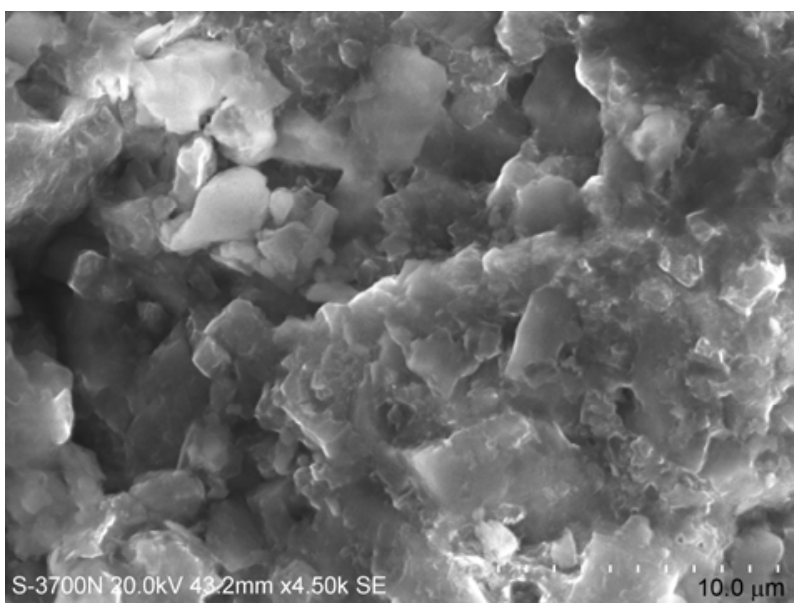

Figure 8 Image of SDG12L5-7879 under SEM. 


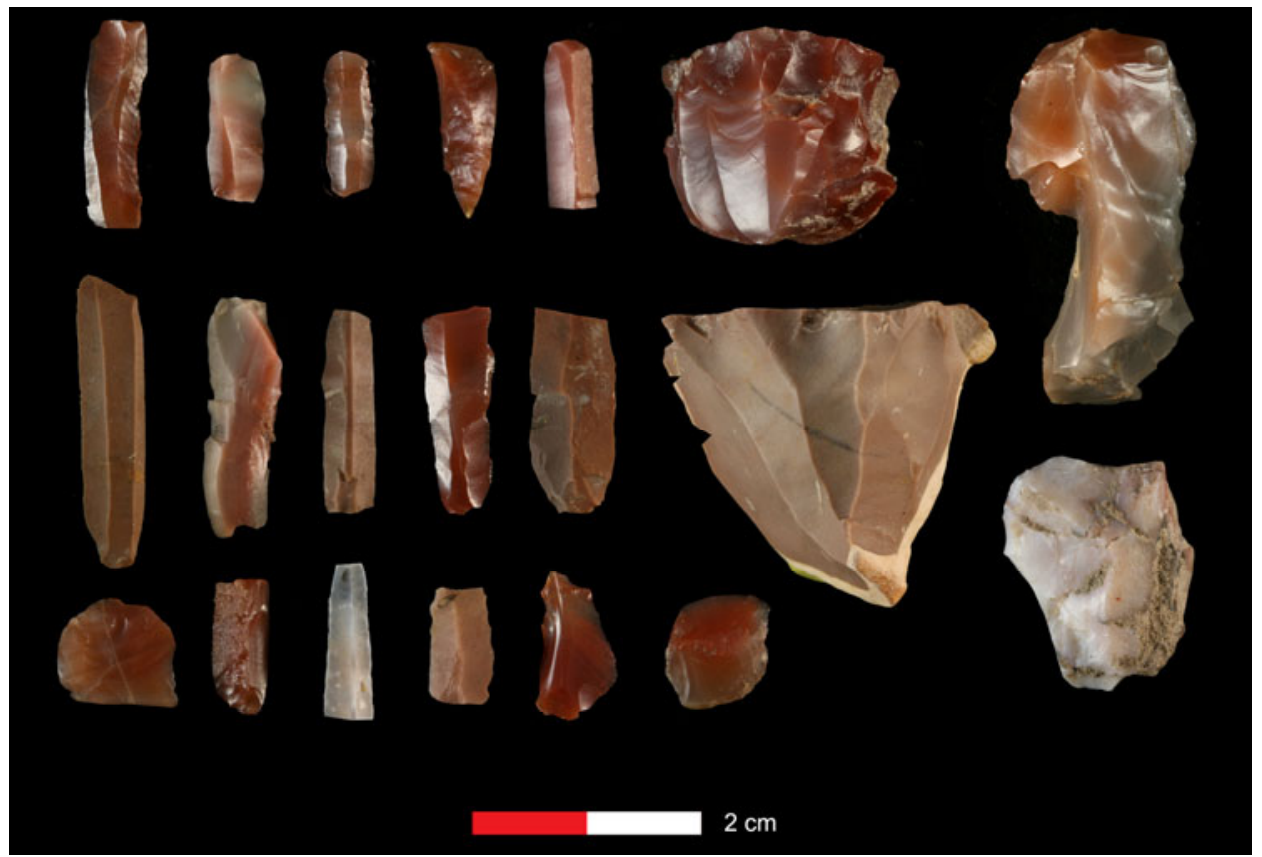

Figure 9 Heat treated artifacts of SDG12.

SDG 12 ( $n=65)$. In SDG 2, 3 coincident burning specimens were identified, 10 in SDG 12. No heated or burned specimens were found in SDG 8 (Table 3). The sampled size is relatively small compared to the complete lithic assemblage; we thus believe that there are more heated stone artifacts in these two localities. Regardless of the sample size, the analyzed specimens cover all typological types.

\section{Discussion}

\subsection{Identification standards of heat-treated artifacts}

This simulation experiment demonstrates that colour change should be one indication for heat-treated artifacts at the SDG site. Although previous studies suggest luster is the most effective identification of heat treatment, this does not

Table 3 Lithic assemblage of heat-treated artifacts in SDG site

\begin{tabular}{|c|c|c|c|c|c|c|c|}
\hline & \multicolumn{3}{|c|}{ SDG2 } & \multicolumn{3}{|c|}{ SDG12 } & \multirow{2}{*}{$\frac{\text { SDG8 }}{\text { Number }}$} \\
\hline & Number $^{a)}$ & Heat treated & Unintentional heating & Number $^{a}$ & Heat treated & Unintentional heating & \\
\hline Cores & 61 & 2 & & 69 & 6 & 2 & 14 \\
\hline Bipolar cores & & & & 40 & & & \\
\hline Tools & & & & 331 & 12 & & 11 \\
\hline Flakes & 1927 & 11 & 1 & 1684 & 46 & 6 & 733 \\
\hline Bipolar flakes & & & & 65 & & & \\
\hline Micro flakes & & & & 44 & 1 & 1 & \\
\hline Debris & 1501 & 9 & 1 & & & & \\
\hline Chunks & 3805 & 23 & 1 & 51 & & 1 & 15 \\
\hline Subtotal & 7294 & 45 & 3 & 2284 & 65 & 10 & 773 \\
\hline \multicolumn{8}{|l|}{ Raw materials } \\
\hline Dolomite & $934(12.8 \%)$ & $6(13.3 \%)$ & & $1163(50.9 \%)$ & $22(33.8 \%)$ & & \\
\hline Chert & $3497(47.9 \%)$ & $39(86.7 \%)$ & & $623(27.3 \%)$ & $19(29.2 \%)$ & & \\
\hline Quartzite sandstone & $2157(29.6 \%)$ & & & $42(1.8 \%)$ & & & \\
\hline Chalcedony & & & & $116(5.1 \%)$ & $23(35.5 \%)$ & & \\
\hline Others & $706(9.7 \%)$ & & & $340(14.9 \%)$ & $1(1.5 \%)$ & & \\
\hline
\end{tabular}

a) The artifacts involved in this paper were part of the total number. 
apply to the stone material in SDG area. This result implied that different types of rock that had been heat-treated may generate different visual changes. In consideration of the subjectivity of the naked eye, it is suggested that scanning electron microscopy, X-ray diffraction, thermoluminescence, paleomagnetism, or other methods should be applied to improve the credibility of heat treatment research.

The results of the experiments involving unintentional heating revealed that it is straightforward to distinguish the artifacts that were heat-treated intentionally from those that we heat-treated unintentionally, with the differences pertaining to the different heating environments. The unintentionally heated blanks were heated in the fire at a minimum starting temperature of $300^{\circ} \mathrm{C}$ and peak temperature of $800^{\circ} \mathrm{C}$ [29], and the specimens were in contact with the fuel. This heating environment led to black carbonizationc, thermal breaking, cracks, changes in lustre, excessive oxidation, etc. These characteristics can be identified by visual observation.

\subsection{Heat treatment in SDG}

Through the examination of heated stone artifacts in SDG, some similarities were found between SDG 2 and SDG 12 despite a 10000-year time gap. For example, (1) the selection of special raw materials. The dominant raw materials in SDG 2 and 12 are all dolomite and chert (Table 3). SDG 12 presents greater preference to these rock types. Also, (2) heattreatment at these two localities was well-controlled in that there is no over-heating of the specimens. It indicates that the ancient occupants mastered the knowledge of suitable temperature and were able to control the fireplace temperature.

In addition, heated stone artifacts in SDG 12 reveal a more advanced heat treatment technique. The main features include: (1) intensive selection of raw materials as chalcedony represents a higher percentage in the heated assemblage; (2) stone artifacts which are heated are predominantly flakes, micro-blades and retouched tools. In terms of size and volume, these specimens presented few differences. At the same time, advanced pressure and soft hammer knapping are the main techniques, which are more conductive for heated materials. Heated specimens are not found among bipolar products. Also, (3) ancient knappers used different heating techniques for different purposes. For instance, almost all the heated scrapers were made of heated chalcedony and $82 \%$ of the heated flakes are made of. Conversely, for micro-blades, dolomite counted for more than $50 \%$ while the proportions of chalcedony and chert were significantly reduced. The silicon content is lower in dolomite compared to chalcedony and chert, and the knapping performance of dolomite is thus not as good as that of highsilicon content rocks. The ancient knappers might have grasped this characteristic and therefore heated the dolomite blanks for micro-blade manufacture. Finally, (4) after heating, the blank could produce more sharp flakes, but with resulting greater brittleness. These characteristics are appropriate for small artifacts, such as scrapers. Although the heating techniques at different localities are subtly diverse, the ancient occupants were able to control the temperature of the fireplace or hearth had already become well-acquired with heating techniques, and had learned the properties of various rocks.

\subsection{The associated early modern human behaviors}

To Paleolithic human beings, heat treatment was a sort of comprehensive technology which required pre-design and the sufficient understanding to different rock types, and it also required the knowledge and use of appropriate heating techniques to produce the final goal of knappable stone. At the same time, the fire should be well-controlled at the optimal temperature. In short, heat treatment is a result of the developed cognition of human beings, is the reflection of advanced resource utilization capability and lithic knapping ability, and is considered as one of the early modern human behaviors.

The heated stone artifacts in SDG 2 and SDG 12 indicate that SDG occupants had already acquired the heat treatment technology. SDG 12 revealed more advanced knapping techniques and resource utilization strategies such as raw material selection, which enhanced the efficiency of micro-blade production by heat treatment and expanded the possible raw material selection by changing the texture of rocks. These discoveries significantly reflect the adaptation to the natural environment by ancient humans. On the other hand, during the SDG 12 occupation period, the natural environment in Shuidonggou area fluctuated greatly and the usable resources decreased compared to the SDG 2 occupation period, which was mainly broad-leaf Savanna. Face with an increasingly harsh environment that challenged their survival, these ancient humans developed more-effective heat treatment techniques. With their success, these ancient humans became more mobile and flexible. This expanded their migratory capacity and broadened the range of their activities to include the sustaining use of plant and animal resources. The evolution of heat-treatment techniques from 10000-20000 years ago is thus considered as a successful, adaptive response of ancient occupants to the changing environment. However, as one of the early modern human behaviors, heat-treatment analysis might not resolve all the associated issues. We expect that further study of additional unearthed cultural relics will reveal clearer understanding of the behaviors of SDG occupants.

\section{Conclusion}

Heated stone artifacts discovered at the SDG site indicate that the heat treatment technique not only aimed to exploit raw materials and change the appearance of rocks, but it 
also focused on enhancing the knapping performance and efficiency. This technique is an important response by humans to the changing natural environment, causing an improvement of survival capabilities. Twenty thousand years ago, SDG occupants had mastered the heat treatment technology. Ten thousand years later, with the evolution of physics and intelligence, they could systematically use this technology. With the other cultural relics such as ostrich egg shell beads, bone artifacts, and hearths, we believe that there is mature modern human behavior at the SDG site.

The oldest heat treatment is documented at Pinnacle Point in South Africa (164-72 ka BP) [15]. Besides this, heat treatment phenomena are also recorded in Europe from 100 to 30 thousand years ago [16,17]. In the Upper Paleolithic period, this technology was widely dispersed in the human world, including Africa, Europe, America, Oceania, West Asia, Middle Asia and South Asia [18,19,36]. Heated stone artifacts at SDG are the earliest evidence of Paleolithic heat treatment in East Asia, which filled in a gap in this research area and shed new light on the study of the dispersal of this technology.

Stone artifacts are a main source of information from the Paleolithic, and it can be informative regarding the cognition of early modern humans and their adaptations to the natural environment. Heat treatment technology provided important technological support for the viability of ancient humans in harsh environments and made it possible for occupants to develop more efficient survival strategies. Heated rocks provided a material for the development of lithic knapping, and they produce more diverse artifact types with more standardization of form. Sophistication and mass production of stone tools considerably promoted the occurrence of ancient exchange behavior; the reddish color of heated stone catered to the conscious need of color and subsequently enhanced the exchange value. A successful heat treatment could not be possible without an appropriate fireplace or hearth and good control of the temperature, which means these abilities had to exist by this time. Deeper and future study of heat treatment technology would provide more perspectives and clues to better understand early modern human behaviors.

We deeply thank Professor Michael Collins and Professor David Madsen for the advising; Professor Chen Shen also gave significant suggestion; we are very grateful to the reviewers for many precious review and revision. This work was supported by the Strategic Priority Research Program of the Chinese Academy of Sciences (XDA05130301; XDA05130303), Specific Basic Research Program of Ministry of Sciences and Technology of China (2007FY110200).

1 Mellars P A. Symbolism, language, and the Neanderthal mind. In: Mellars P, Gibson K R, eds. Modelling the Early Human Mind. Cambridge: McDonald Institute Monographs, 1996. 15-32

2 Chase P G, Dibble H L. Middle Paleolithic symbolism: A review of current evidence and interpretations. J Anthropol Archaeol, 1987, 6: 263-296

3 Renfrew C. The sapient behaviour paradox. In: Mellars P, Gibson K
R, eds. Modelling the Early Human Mind. Cambridge: McDonald Institute Monographs, 1996. 11-14

4 Gargett R H. Middle Palaeolithic burial is not a dead issue: The view from Qafzeh, Saint-Césaire, Kebara, Amud, and Dederiyeh. J Hum Evol, 1999, 37: 27-90

5 Christopher S H. The origin of modern human behavior-critique of the models and their test implications. Current Anthropol, 2003, 44: $627-651$

6 Bar-Yosef O. The Upper Paleolithic evolution. A Rev Anthropol, 2002, 31: 363-393

7 Mellars P A. Major issues in the origin of modern humans. Current Anthropol, 1989, 30: 349-385

8 Mellars P A. Technological changes across the Middle-Upper Paleolithic transition: Economic, social, and cognitive perspectives. In: Mellars P, Stringer C, eds. The Human Revolution: Behavioral and Biological Perspectives on the Origins of Modern Humans. Edinburgh and Princeton: University Press, 1989. 338-365

9 Chase P G, Dibble H L. On the emergence of modern humans. Current Anthropol, 1990, 38: 58-59

10 Klein R G. Anatomy, behavior, and modern human origins. J World Prehist, 1995, 9: 167-198

11 Ambrose S H. Chronology of the Later Stone Age and food production in East Africa. J Archaeol Sci, 1998, 25: 377-392

12 Deacon H J. Modern human emergence: An African archaeological perspective. In: Tobias P V, Raath M A, Maggi-Cecchi J, eds. Humanity From African Naissance to Coming Millennia: Colloquia in Human Biology and Palaeoanthropology. Florence: University of Florence Press, 2001. 217-226

13 Milo R G. Evidence for hominid predation at Klasies River Mouth, South Africa, and its implications for the behavior of early modern humans. J Archaeol Sci, 1998, 25: 99-133

14 Thackeray A L. The Middle Stone Age south of the Limpopo River. J World Prehist, 1992, 6: 385-440

15 Brown K S, Marean C W. Fire as an engineering tool of early modern humans. Science, 2009, 325: 859-862

16 Copeland L. The Middle Paleolithic flint industry of Ras el-Kelb. In: Copeland L, Moloney N, eds. The Mourterian Site of Ras el-Kelb, Lebanon. Oxford: B.A.R., 1998. 73-101

17 Duttine M P. Effects of thermal treatment on TL and EPR of flints and their importance in TL-Dating: Application to French Mousterian sites of Les Forets (Dordogne) and Jiboui (Drome). Radiat Meas, 2005, 39: 375-385

18 Domanski M, Webb J. A review of heat treatment research. Lithic Tech, 2007, 32: 153-194

19 Clark J D, Williams M A. Paleoenvironments and prehistory in North Central India: A preliminary report. In: Jacobson J, ed. Studies in Archaeology of India and Pakistan. New Delhi: American Institute of Indian Studies, 1986. 19-41

20 Liu D, Wang X, Gao X, et al. Progress in the stratigraphy and geochronology of the Shuidonggou site, Ningxia, North China. Chin Sci Bull, 2009, 54: 3880-3886

21 Gao X, Yuan B, Pei S, et al. Analysis of sedimentary-geomorphologic variation and the living environment of hominids at the Shuidonggou Paleolithic site. Chin Sci Bull, 2008, 53: 2025-2032

22 Wang C. Debitage Analysis and Experimental Study on Locality 8 of Shuidonggou Site (in Chinese). Dissertation for the Doctoral Degree. Beijing: Institute of Vertebrate Paleontology and Paleoanthropology. 2010

23 Zheng $\mathrm{Z}, \mathrm{Li}$ Y. The new advances in the study of the ordovidian system in Helanshan Area (in Chinese). Geoscience, 1991, 5: 119-137

24 Liao H. Geological characteristics of Ningxia Hui Autonomous Region (in Chinese). Chin Reg Geol, 1989: 314-323

25 Ningxia Archaeological Institute. Shuidonggou-1980 Excavation Report (in Chinese). Beijing: Science Press, 2003

26 Madsen D B, Li J, Brantingham P J, et al. Dating Shuidonggou and the Upper Paleolithic blade industry in North China. Antiquity, 2001, 75: 706-716

27 Gao X, Li J, Madsen D B, et al. New ${ }^{14} \mathrm{C}$ dates for Shuidonggou and related discussions (in Chinese). Acta Anthropol Sin, 2002, 21: 211-218 
28 Gao X, Pei S. An archaeological interpretation of ancient human technology and adaptive strategiesin China (in Chinese). Quat Sci, 2006, 26: 504-513

29 Gao X, Wang H, Liu D, et al. A study of fire-use activities at Shuidonggou Locality 12 (in Chinese). Acta Anthropol Sin, 2009, 28: 329-336

30 Gao X, Zhang X L, Yang D Y, et al. Revisiting the origin of modern humans in China and its implications for global human evolution. Sci China Earth Sci, 2010, 1927-1940

31 Collins M B, Fenwick J M. Heat treating of chert: Methods of interpretation and their application. Plains Anthropol, 1974, 19: 134-145

32 Bleed P, Maier M. An objective test of the effects of heat treatment of flakeable stone. Am Antiquity, 1980, 45: 502-507

33 Purdy B A. Investigations concerning the thermal alternation of silica minerals: an archaeological approach. Tebiwa, 1974, 17: 37-66

34 Domanski M, Webb J. Effect of heat treatment on siliceous rocks used in prehistoric lithic technology. J Archaeol Sci, 1992, 19: 601-614

35 Joyce D J. Heat treatment of Alibates Chalcedony. Lithic Tech, 1985, 14: 36-40

36 Domański M, Webb J, Glaisher R, et al. Heat treatment of polish flints. J Archaeol Sci, 2009, 36: 1400-1408

37 Guan Y, Gao X, Wang H M, et al. Spatial analysis of intra-site use at a Late Paleolithic site at Shuidonggou, Northwest China. Chin Sci Bull, 2011, 56: 3457-3463

Open Access This article is distributed under the terms of the Creative Commons Attribution License which permits any use, distribution, and reproduction in any medium, provided the original author(s) and source are credited. 